DOI: 10.5902/19834659 21749

\title{
APRENDIZAGEM ORGANIZACIONAL COM A IMPLEMENTAÇÃO E MANUTENÇÃO DA ISO 14001: UM ESTUDDO EXPLORATÓRIO EM UMA EMPRESA DE AUTOPEÇAS
}

\author{
ORGANIZATIONAL LEARNING WITH THE IMPLEMENTATION \\ AND MAINTENANCE OF ISO 14001: AN EXPLORATORY STUDY \\ IN AN AUTOPARTS COMPANY
}

Data de submissão: 08-04-2016 Aceite: $13-11-2016$

Carlos Jonathan Da Silva Santos ${ }^{1}$ Juscely Reis Matos ${ }^{2}$

\section{RESUMO}

O objetivo deste estudo, considerado exploratório, é identificar a aprendizagem no nível organizacional de uma empresa de autopeças com a implementação e manutenção do Sistema de Gestão Ambiental (SGA) conforme a norma ISO 14001. Para isso, apoia-se em referencial teórico que entende a aprendizagem organizacional como um produto ou um processo. A fim de compreender a aprendizagem organizacional, considerou-se pertinente entrevistar duas pessoas fundamentais no processo de implementação e manutenção da ISO 14001. Suas descrições foram interpretadas hermeneuticamente por análise indutiva e resultaram na compreensão de que houve, no processo de implementação e manutenção da norma ISO 14001, a geração de um produto, que foi a aprendizagem da organização relacionada com a gestão ambiental.

Palavras-chave: Aprendizagem Organizacional, Sistema de Gestão Ambiental (SGA), ISO 14001.

Possui graduação em Administração pela Universidade Presbiteriana Mackenzie, MACKENZIE e mestrado em Administração de Empresas pela Universidade Presbiteriana Mackenzie, MACKENZIE. Taboão da Serra. São Paulo. Brasil. E-mail: carlos.jonathan@icloud.com 2 Possui graduação em Administração de empresas pela Universidade Presbiteriana Mackenzie. Taboão da Serra. São Paulo. Brasil. E-mail: juscelyreis@hotmail.com 


\section{ABSTRACT}

The aim of this study, considered exploratory, is to identify the learning on organizational level of an auto parts company with the implementation and maintenance of an Environmental Management System according to the rules of ISO 14001. It relies on the theoretical framework that focuses on organizational learning as a product or a process producing a product. To get an understanding of organizational learning was considered appropriate to interview two key people in the implementation and maintenance of ISO 14001. Their descriptions were hermeneutically interpreted by inductive analysis process and resulted in the understanding that the company studied had, in the process of implementation and maintenance of the ISO 14001, the generation of a product, that was organizational learning relating with the management of the environment.

Keywords: Organizational Learning, Environmental Management System, ISO 14001.

\section{INTRODUÇÃO}

A norma ISO 14001 enfatiza que as organizações estão cada vez mais preocupadas em desenvolver Sistemas de Gestão Ambiental (SGA) que sejam capazes de demonstrar um correto desempenho ambiental por meio do controle dos impactos de suas atividades, seus produtos ou seus serviços. Barbieri (2007, p. 147) define SGA como "um conjunto de atividades administrativas e operacionais inter-relacionadas para abordar os problemas ambientais atuais ou para evitar o seu surgimento".

Diante disso, este estudo foi realizado em uma empresa do setor de autopeças que implementou seu SGA, conforme a ISO 14001, no ano de 2001. O setor de autopeças é fundamental na cadeia de produção automotiva, representando uma importante participação na indústria brasileira. Conforme o anuário do desempenho do setor de autopeças 2015, realizado pelo Sindipeças e pela Abipeças, em 2014, os cerca de 500 associados dessas duas instituições registraram um faturamento de 76,8 bilhões de reais, sendo os negócios com as montadoras responsáveis por $67,5 \%$ desse valor. Esses números mostram que, além da importância das empresas de autopeças para o cenário brasileiro, a manutenção dos negócios dessas empresas com as montadoras de automóveis é crucial.

Tratar das questões relacionadas ao meio ambiente passou a ser exigência de muitas montadoras para com seus fornecedores de peças. Em vista disso, as empresas de autopeças que não se anteciparam ou identificaram a necessidade de criação do SGA, mas tiveram de implementá-lo por pressão dos seus clientes.

Nesse contexto, é crescente o número de empresas que estão aderindo à ISO 14001. A Revista Meio Ambiente Industrial, por exemplo, divulgou, em maio de 2011, uma matéria que mostrava que cinco mil empresas no Brasil já haviam obtido a certificação de conformidade ambiental com a norma ISO 14001. Entende-se que, ao implementar o SGA, a empresa passa a tratar de seus problemas ambientais, existentes ou potenciais, de maneira mais estruturada, sendo necessárias ações para que o sistema continue ativo e que a empresa aprenda por meio de suas práticas. Nesse processo de manutenção de um SGA, evidencia-se a ocorrência de aprendizagem organizacional.

Bontis, Crossan e Hulland (2002) apresentam um compilado de definições de diferentes autores sobre aprendizagem organizacional. Fiol e Lyles (1985) consideram que a organização que aprende é uma organização hábil na criação, aquisição e transferência de conhecimento e é capaz de modificar seu comportamento para gerar novos conhecimentos e insights. Senge (1990), por sua vez, afirma que as organizações que aprendem são organizações em que as pessoas expandem continuamente sua capacidade de criar os resultados que realmente desejam, em que novos e expansivos padrões de pensamento são nutridos, em que as aspirações coletivas 
são libertadas e em que as pessoas estão constantemente aprendendo como aprender juntas. Kim (1993) define a aprendizagem organizacional como o aumento de capacidade da organização para tornar uma ação efetiva. Já para Schwandt e Marquardt (2000), a aprendizagem organizacional representa uma complexa inter-relação entre as pessoas, suas ações, os símbolos e os processos dentro da organização.

Porém, a definição considerada como crucial nesta pesquisa não faz parte do compilado de Bontis, Crossan e Hulland (2002). Essa definição é a de Argyris e Schön (1996), para quem a aprendizagem pode ser tanto um produto (algo que se aprende) quanto um processo que produz um produto. De forma genérica, uma organização aprende à medida que adquire informações (conhecimento, compreensão, know-how, técnicas ou práticas) de qualquer tipo e por qualquer meio. Outra definição que tem forte relação com este estudo é a de Argyris e Schön (1978), para os quais a aprendizagem organizacional é um processo de detecção e correção de erros.

Partindo dessas definições sobre aprendizagem organizacional, é possível estabelecer uma relação com a metodologia utilizada pela ISO 14001 conhecida como ciclo PDCA (Plan-DoCheck-Act, ou seja, Planejar-Executar-Verificar-Agir). Nesse ciclo, após o planejamento, o plano é executado e depois verificado, para que, então, sejam tomadas as devidas ações para a manutenção do sistema, iniciando-se todo o processo novamente. Essa relação entre ciclo PDCA e aprendizagem organizacional pode ser identificada, principalmente, na fase de verificação do PDCA, já que, conforme Argyris e Schön (1978), a aprendizagem organizacional é um processo de deteç̧ão e correção de erros. Nas auditorias internas e externas do sistema ambiental, em que esse ciclo acontece, à medida que o processo é iniciado novamente, a forma de lidar com os pontos identificados e a tratativa tornam-se diferentes, havendo um acúmulo de conhecimento pela empresa e, consequentemente, uma capacidade de modificar comportamentos.

A partir dos conceitos apresentados, pode-se indagar: como ocorreu a aprendizagem no nível organizacional de uma empresa do setor de autopeças com a implementação e manutenção do SGA conforme a ISO 14001? O objetivo deste estudo consiste, assim, em identificar a aprendizagem no nível organizacional de uma empresa de autopeças com a implementação e manutenção do SGA conforme a ISO 14001. Para atingir esse objetivo, a seguir, apresenta-se a discussão teórica sobre aprendizagem no nível organizacional. Posteriormente, trata-se da implementação do SGA conforme a norma ISO 14001. Por fim, são apresentados os aspectos metodológicos e os resultados do estudo.

\section{APRENDIZAGEM NO NÍVEL ORGANIZACIONAL}

Observa-se ao longo do referencial teórico que não há uma única definição para aprendizagem organizacional. Dessa maneira, são apresentadas algumas definições, ressaltando-se que a de Argyris e Shön (1996) é a que sustenta este estudo.

Easterby-Smith e Lyles (2003) sugerem que Cyert e March foram os primeiros autores a fazerem referência à aprendizagem organizacional, o que ocorreu em 1963. Desde Cyert e March (1963), que falaram pela primeira vez em aprendizagem organizacional, e, especialmente, a definição de Argyris e Schön, em A Theory of Action Pespective (1978), o conceito tem sido usado de diferentes maneiras e em diferentes tradições disciplinares. A quantidade de literatura publicada sobre o assunto nas últimas duas décadas tem sido esmagadora. Embora exista ampla aceitação da noção de aprendizagem organizacional e da sua importância para o desempenho estratégico, não há uma teoria ou um modelo de aprendizagem organizacional amplamente aceito (PAWLOWSKY, 2001).

Para Antal et al. (2001), redes de experiência de trabalho conjunto, comunidades de prática e cultura organizacional são elementos importantes para o estudo da aprendizagem orga- 
nizacional. A aprendizagem organizacional é multidimensional: ela atravessa as fronteiras organizacionais e afeta os recursos humanos das organizações, sendo, por conseguinte, afetada pela governança das organizações e pela boa vontade de alguns em assumir o papel de professor e aluno (EASTERBY-SMITH; LYLES 2003).

Nonaka e Takeuchi (1995) compreendem a aprendizagem organizacional como um processo em que se constitui determinado conhecimento organizacional capaz de demonstrar a inovação que ocorre a partir de rupturas bruscas e de mudanças incrementais nos processos. Nesse sentido, a aprendizagem pode ser tanto um produto (algo que se aprende) quanto um processo que produz um produto. De forma genérica, uma organização aprende à medida que adquire informações (conhecimento, compreensão, know-how, técnicas ou práticas) de qualquer tipo e por qualquer meio (ARGYRIS; SCHÖN, 1996).

Alguns cientistas sociais foram resistentes à ideia de aprendizagem organizacional, pois, para eles, apenas indivíduos poderiam pensar, raciocinar ou ter opiniões. Contudo, atualmente, é cada vez mais comum encontrar pessoas que atribuem às equipes, aos departamentos ou às organizações atividades como pensamento, lembranças e aprendizagem (ARGYRIS; SCHÖN, 1996).

Para Argyris e Schön (1996), não é possível falar de aprendizagem organizacional sem compreender a ideia da ação organizacional, já que, logicamente, a ação precede a aprendizagem organizacional. Argyris e Schön (1996) concebem a aprendizagem organizacional a partir de três ciclos: único, duplo e deuteroaprendizagem. A aprendizagem de ciclo único é a aprendizagem instrumental que muda estratégias de uma determinada ação, sem alterar os valores de uma teoria. Dessa maneira, essas estratégias são modificadas para manter o desempenho organizacional dentro do intervalo definido pelos valores e pelas normas existentes na organização. Já na aprendizagem de ciclo duplo, antes da efetivação de uma ação, os resultados anteriores são corrigidos a partir de um exame dos princípios de base do sistema. A aprendizagem de ciclo duplo envolve, assim, a revisão crítica da teoria em uso por meio do questionamento dos princípios e das regras vigentes, que são, então, adequadamente alterados (ARGYRIS; SCHON, 1996).

A distinção entre aprendizagem de ciclo duplo e ciclo simples é complicada por conta de vários elementos. Um desses elementos consiste no tamanho e na complexidade organizacional. As grandes organizações são compostas de muitas camadas, que existem não apenas como abstrações, mas como entidades vivas, de modo que cada uma dessas entidades pode ser descrita como tendo interesses, intenções, valores e teoria em uso peculiar. Dessa maneira, do ponto de vista de cada uma dessas entidades, o resto da organização é o meio ambiente (ARGYRIS; SCHÖN, 1996). Outro elemento que dificulta a distinção entre aprendizagem de circuito duplo e simples é a relação entre produtos e processos de aprendizagem (ARGYRIS; SCHÖN, 1996).

A deuteroaprendizagem organizacional, por sua vez, indica a capacidade de aprender a aprender. $O$ sistema de aprendizagem de uma organização é composto de estruturas que canalizam a investigação organizacional e o mundo comportamental da organização. Tais estruturas, por facilitarem a investigação organizacional, são denominadas de facilitadores. Compreende-se que o sistema de aprendizagem de uma organização é interdependente das teorias em uso que as pessoas trazem do seu mundo comportamental, pois tais teorias ajudam a criar e manter o sistema de aprendizado da organização. Desse modo, a deuteroaprendizagem ocorre quando os membros de uma organização descobrem e modificam o sistema de aprendizagem (ARGYRIS; SCHÖN, 1996).

Pouco se sabe sobre o papel do conhecimento e da aprendizagem como um promotor de mudanças e de acréscimo de valor. Dessa forma, um dos principais desafios para a gestão é compreender a função do conhecimento e da aprendizagem para a mudança organizacional e para o sucesso empresarial (PAWLOWSKY, 2001). 
Desde que se tornou evidente que não existe uma maneira melhor de gerenciar uma organização em todas as circunstâncias, tem se levantado o questionamento sobre qual a solução que melhor se adapta às circunstâncias. Dessa maneira, a abordagem de aprendizagem organizacional permite considerar a aprendizagem não apenas como adaptação às contingências, mas também como percepção, compreensão e interpretação (PAWLOWSKY, 2001).

Além das abordagens apresentadas, Bontis, Crossan e Hulland (2002) realizam uma análise e demonstram as diversas definições de aprendizagem organizacional, expostas a seguir no Quadro 1.

Quadro 1: Definições de Aprendizagem Organizacional

\begin{tabular}{|c|c|}
\hline $\begin{array}{l}\text { Argyris e Schön } \\
\text { (1978) }\end{array}$ & A aprendizagem organizacional é um processo de detecção e correção de erros. \\
\hline Fiol e Lyles (1985) & $\begin{array}{l}\text { A aprendizagem organizacional é o processo de aprimoramento das ações por } \\
\text { meio do conhecimento e da compreensão. }\end{array}$ \\
\hline Daft e Weick (1984) & $\begin{array}{l}\text { A aprendizagem organizacional é o conhecimento sobre as inter-relações entre a } \\
\text { ação da organização e do ambiente. }\end{array}$ \\
\hline Levitt e March (1988) & $\begin{array}{l}\text { As organizações aprendem à medida que codificam aquilo que inferem ser corre- } \\
\text { to; tal inferência ocorre a partir das histórias e das próprias rotinas desempenha- } \\
\text { das dentro das organizações. }\end{array}$ \\
\hline Stata (1989) & $\begin{array}{l}\text { A aprendizagem organizacional é o principal processo pelo qual a inovação ocor- } \\
\text { re, de modo que a taxa na qual os indivíduos e as organizações aprendem pode } \\
\text { se tornar a única vantagem competitiva sustentável, especialmente em indústrias } \\
\text { intensivas em conhecimento. }\end{array}$ \\
\hline Senge (1990) & $\begin{array}{l}\text { As organizações que aprendem são organizações onde as pessoas expandem con- } \\
\text { tinuamente sua capacidade de criar os resultados que realmente desejam, onde } \\
\text { novos e expansivos padrões de pensamento são nutridos, onde as aspirações } \\
\text { coletivas são libertadas e onde as pessoas estão constantemente aprendendo a } \\
\text { aprender juntas. }\end{array}$ \\
\hline Huber (1991) & $\begin{array}{l}\text { Uma entidade aprende se, por meio de seu processamento de informações, ela } \\
\text { muda de comportamento. }\end{array}$ \\
\hline Lee et al. (1992) & $\begin{array}{l}\text { O processo de aprendizagem organizacional é visto como um ciclo em que as } \\
\text { ações dos indivíduos levam às interações organizacionais com o meio ambiente, } \\
\text { já que respostas ambientais são interpretadas por indivíduos que aprendem por } \\
\text { meio da atualização de suas crenças sobre relações de causa-efeito. }\end{array}$ \\
\hline MCyCr-Dohm (1992) & $\begin{array}{l}\text { A aprendizagem organizacional é o ato contínuo e transformador da experiência } \\
\text { em conhecimento compartilhado que a organização acessa e utiliza para atingir } \\
\text { o seu propósito. }\end{array}$ \\
\hline Mills e Friesen (1992) & $\begin{array}{l}\text { Uma organização que aprende sustenta a inovação interna com os objetivos ime- } \\
\text { diatos de melhorar a qualidade, melhorando o relacionamento com clientes e } \\
\text { fornecedores ou executando eficazmente a estratégia de negócios. }\end{array}$ \\
\hline N Adler et al. (1992) & $\begin{array}{l}\text { Aprendizagem requer um ambiente no qual os resultados dos experimentos são } \\
\text { encontrados, analisados e divulgados em toda a organização. }\end{array}$ \\
\hline Garvin (1993) & $\begin{array}{l}\text { A organização que aprende é uma organização hábil na criação, aquisição e trans- } \\
\text { ferência de conhecimento e capaz de modificar seu comportamento para gerar } \\
\text { novos conhecimentos e insights. }\end{array}$ \\
\hline $\operatorname{Kim}(1993)$ & $\begin{array}{l}\text { A aprendizagem organizacional é definida como o aumento de capacidade de or- } \\
\text { ganização para torar a ação efetiva. }\end{array}$ \\
\hline $\begin{array}{l}\text { Levinthal e } \\
\text { March (1993) }\end{array}$ & $\begin{array}{l}\text { A aprendizagem organizacional lida com o problema de equilibrar a competição } \\
\text { de novas metas de desenvolvimento e conhecimento e explorar as competências } \\
\text { atuais em face das tendências dinâmicas. }\end{array}$ \\
\hline Day (1994) & $\begin{array}{l}\text { A aprendizagem organizacional é composta dos seguintes processos: abrir a men- } \\
\text { te, questionar, informar interpretações e ter memória acessível. }\end{array}$ \\
\hline Crossan et al. (1995) & $\begin{array}{l}\text { A aprendizagem é um processo de mudança na cognição e no comportamento, o } \\
\text { que não significa necessariamente mudança no desempenho. }\end{array}$ \\
\hline
\end{tabular}




\begin{tabular}{|c|l|}
\hline $\begin{array}{c}\text { Slater e Narver } \\
\text { (1995) }\end{array}$ & $\begin{array}{l}\text { Na sua definição mais básica, a aprendizagem organizacional é o desenvolvimento } \\
\text { de novos conhecimentos ou insights que têm o potencial de influenciar o com- } \\
\text { portamento. }\end{array}$ \\
\hline $\begin{array}{c}\text { Cavaleri e } \\
\text { Fearon (1996) }\end{array}$ & $\begin{array}{l}\text { A aprendizagem organizacional é a criação proposital de significados compartilha- } \\
\text { dos oriundos das experiências comuns das pessoas nas organizações. }\end{array}$ \\
\hline Marquardt (1996) & $\begin{array}{l}\text { Uma organização que aprende poderosamente, coletivamente e continuamente a se } \\
\text { transformar para melhorar o fluxo, gerenciar e usar o conhecimento para o sucesso. }\end{array}$ \\
\hline Miller (1996) & $\begin{array}{l}\text { Aprender é diferente de tomada de decisão, já que a aprendizagem pode ocorrer } \\
\text { de fato muito tempo antes ou muito depois da tomada de decisão. }\end{array}$ \\
\hline $\begin{array}{c}\text { Schwandt e } \\
\text { Marquardt (2000) }\end{array}$ & $\begin{array}{l}\text { A aprendizagem organizacional representa uma complexa inter-relação entre as } \\
\text { pessoas, suas ações, os símbolos e os processos dentro da organização. }\end{array}$ \\
\hline
\end{tabular}

Smith (2012) destaca a importância da aprendizagem organizacional para a sustentabilidade das organizações e afirma que a aprendizagem organizacional é tipicamente considerada como "detecção e correção de erros", sendo erro uma discrepância entre o que os membros de um contexto organizacional aspiram atingir e o que eles realmente atingem. Assim, a sustentabilidade organizacional é definida como:

O resultado das atividades de uma organização, voluntárias ou baseadas em leis, que demonstram a capacidade de uma organização para manter viáveis as suas operações comerciais (incluindo viabilidade financeira, conforme o caso), não impactando negativamente os sistemas sociais ou ecológicos. (SMITH; SCHARICZ, 2011 apud SMITH, 2012, p.5).

As várias definições apresentadas demonstram a variedade de abordagens de aprendizagem organizacional existentes. No caso de um SGA baseado na ISO 14001, à medida que os problemas (erros) identificados forem solucionados de modo eficaz, a reincidência desses problemas tende a diminuir ou cessar de forma definitiva. Assim, com o tempo, a gestão do SGA torna-se madura e passa a acontecer de forma automática, demonstrando um aprendizado ao longo do tempo.

\section{SISTEMA DE GESTÃO AMBIENTAL CONFORME ISO 14001}

Pereira e Curi (2012) afirmam que a ISO (International Organization for Standardization) foi fundada em 1947, com a finalidade de melhorar o comércio entre países, por meio da criação de regras internacionais. Na década de 1990, a gestão ambiental foi abarcada pela ISO, surgindo, dessa forma, a ISO 14000, que inclui normas sobre SGA, auditoria, ciclo de vida do produto e rotulagem ambiental.

A norma sobre SGA é conhecida no Brasil como NBR ISO 14001 - Sistema de Gestão Ambiental. Ela é a única norma da série que concede certificação (PEREIRA; CURI, 2012).

Conforme a ISO 14001, o PDCA é uma forma eficiente de identificar e corrigir problemas de um SGA (PEREIRA; CURI, 2012). O PDCA abarca os seguintes passos: planejar, que envolve estabelecer os objetivos e processos necessários para atingir os resultados em concordância com a política ambiental da organização; executar, que implica implementar os processos; verificar, que consiste em monitorar e medir os processos em conformidade com a política ambiental, os objetivos, as metas e os requisitos legais e relatar os resultados; e, por fim, agir para continuamente melhorar o desempenho do sistema de gestão ambiental (ISO 14001:2004) (Figura 1). 
Figura 1: Espiral do sistema de gestão para melhorar o desempenho do SGA

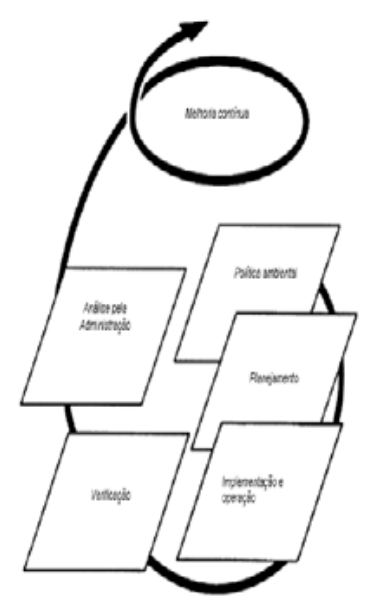

Fonte: ISO 14001:2004

Conforme Gavronski et al. (2013), a decisão de uma empresa de obter a certificação do SGA envolve três motivações: grupo de foco interno, grupo de foco externo e grupo holístico. $O$ grupo de foco interno é caracterizado pela ênfase nas operações e nos recursos internos visando ao melhor uso desses recursos e das capacidades. $\mathrm{O}$ grupo com foco externo, por sua vez, é dirigido pelas expectativas do mercado e pelo desejo de reconhecimento por outras instituições e pelos stakeholders por meio do isomorfismo (DIMAGGIO; POWELL, 2005). Já o grupo holístico valoriza de forma igual todas as dimensões de motivação, independentemente se elas são internas ou externas.

Como este estudo se destina a entender os motivos que impulsionaram uma empresa de autopeças de grande porte a implementar o SGA em conformidade com a norma ISO 14001, é importante compreender melhor o setor em que a empresa pesquisada está inserida. O Sindipeças e a Abipeças desenvolvem o anuário do desempenho do setor de autopeças. No ano de 2015, esse relatório mostrou o desempenho do setor considerando os últimos 20 anos, ou seja, de 1993 a 2014. Alguns indicadores, como faturamento, investimento, produção física industrial e número de funcionários, são apresentados e demonstram um crescimento considerável do setor no período analisado. Outro dado importante presente pelo relatório trata da relevância das montadoras de automóveis para o faturamento das empresas do setor de autopeças, já que aquelas representam $67,5 \%$ do valor faturado.

Pombo e Magrini (2008) apresentam um quadro com o percentual de certificações ISO 14001 emitidas por setor no Brasil, proporcionado identificar os setores predominantes no contexto da certificação ambiental. O quadro mostra que o setor com maior percentual é o automotivo (14\%), seguido do petroquímico (9\%), do químico (8\%), da metalúrgico (6\%) e de outros com percentual menor.

Visto que a empresa pesquisada está inserida em um setor preocupado com as questões ambientais e pioneiro na padronização de seu SGA de acordo com a norma ISO 14001, analisa-se, a seguir, quais itens são mais relevantes dentro do SGA. O gerenciamento de resíduos pode ser considerado um dos itens da norma mais difíceis de ser implementado. Segundo Reis e Garcia (2012),

O setor industrial tem aplicado programas de gestão empresarial direcionados aos resíduos industriais, particularmente aqueles voltados à minimização da geração, reutilização e reciclagem que vem se tornando ferramentas poderosas no combate ao desperdício e ao uso racional dos recursos naturais (p. 456). 
De acordo com a ISO 14001, a organização deve estabelecer, implementar e manter procedimentos para identificar os aspectos ambientais de suas atividades, seus produtos ou seus serviços, levantando os que possuem impactos significativos sobre o meio ambiente. A norma define aspecto como elementos das atividades ou produtos que podem interagir com o meio ambiente e impacto como qualquer modificação no meio ambiente, adversa ou benéfica, que resulte, em todo ou em parte, dos aspectos ambientais de uma organização. Dessa forma, o levantamento de aspectos e impactos dentro de uma organização faz parte do gerenciamento dos resíduos.

A Lei n.o 12.305, de 02 de agosto de 2010, define o gerenciamento de resíduos sólidos como conjunto de ações exercidas, direta ou indiretamente, nas etapas de coleta, transporte, transbordo, tratamento e destinação final ambientalmente adequada dos resíduos sólidos e disposição final ambientalmente adequada dos rejeitos, de acordo com plano municipal de gestão integrada de resíduos sólidos ou com plano de gerenciamento de resíduos sólidos. Embora essa lei seja específica para tratativa dos resíduos sólidos, tal definição é válida para os resíduos industriais, os quais são classificadas por essa mesma lei como resíduos gerados nos processos produtivos e nas instalações industriais.

\section{ASPECTOS METODOLÓGICOS}

Para Merriam (2002), um estudo interpretativo é realizado quando o pesquisador está interessado em compreender como as pessoas interpretam suas experiências, que significado concedem para tais experiências e como constroem seus mundos. O paradigma interpretativista estabelece que a sociedade é compreendida a partir do ponto de vista do participante em ação (MORGAN, 2005).

De acordo com Creswell (2010), é possível compreender um objeto de estudo gradualmente por meio da pesquisa qualitativa. A opção por tal método conduz o pesquisador a demonstrar o significado de um fenômeno à luz da percepção dos entrevistados, motivo pelo qual foram realizadas entrevistas semiestruturadas para compreender o fenômeno da aprendizagem organizacional que ocorreu com a implementação da norma ISO 14001.

Escolheu-se como caso para estudo uma empresa de grande porte do setor de autopeças, com sede nos Estados Unidos. A pesquisa foi realizada em uma unidade produtiva localizada em São Paulo.

Os entrevistados foram selecionados por amostragem proposital (STAKE, 1994), consistindo em duas pessoas fundamentais na implementação e na condução da ISO 14001 na organização estudada. Um entrevistado é representante ambiental, respondendo por todos os assuntos relacionados ao sistema ambiental, e o outro entrevistado é coordenador do sistema, sendo responsável por todas as atividades de planejamento e condução do sistema ambiental, como auditorias internas e externas. Para preservar a identidade dos participantes da presente pesquisa, os mesmos foram identificados como E1 (entrevistado número 1) e E2 (entrevistado número 2).

Quadro 2: Perfil resumido dos entrevistados

\begin{tabular}{|c|c|c|c|}
\hline ENTREVISTADO & GÊNERO & TEMPO NA EMPRESA & CARGO \\
\hline E1 & Feminino & 16 anos & Coordenadora \\
\hline E2 & Masculino & 8 anos & Gerente/Representante ambiental \\
\hline
\end{tabular}

A análise e interpretação das entrevistas foram realizadas considerando-se a base teórica de aprendizagem organizacional, já que, conforme Godoi e Mattos (2006), a dimensão central da validade dos resultados de uma entrevista reside na correspondência entre as pro- 
duções geradas pela entrevista e o modelo teórico da pesquisa. Assim, alguns trechos das falas dos entrevistados foram incluídos para demostrar consistência com a teoria abordada.

\section{RESULTADOS}

A aprendizagem pode ser tanto um produto (algo que se aprende) quanto um processo. De forma genérica, uma organização aprende à medida que adquire informações (conhecimento, compreensão, know-how, técnicas ou práticas) de qualquer tipo e por qualquer meio (ARGYRIS; SCHÖN, 1996). De acordo com tal afirmação, infere-se que a aprendizagem ocorre quando a organização adquire informações. Na empresa estudada, um dos entrevistados relatou que a empresa já tratava dos efluentes e dos resíduos, mas que esse processo foi melhorado com a implementação da ISO 14001. Outro entrevistado afirmou que, conforme as auditorias aconteciam, a organização aprendia e preenchia as lacunas faltantes:

[...] eles tratavam em relação aos influentes e aos resíduos, mas, depois que entrou a ISO 14001, isso foi sistematizado, foi detalhado e ampliado [...] ela foi ampliada de lá pra cá, a gente foi ampliando algumas coisas, alguns assuntos [...] (E1).

[...] você começa com um sistema [...] e vai ter lacunas, mas as próprias auditorias subsequentes, tanto interna quanto externa, vão ajustando essas lacunas, a gente vai preenchendo [...] (E2).

Argyris e Schön (1996) afirmam que um tipo importante de aprendizagem organizacional consiste na melhoria do desempenho de determinada tarefa e que essa aprendizagem se refere à eficácia de uma ação para atingir os objetivos estabelecidos. A esse respeito, um dos entrevistados explicitou que a implementação da ISO 14001 foi importante para que a organização mudasse a maneira de mensurar os indicadores de consumo de energia elétrica e de água. Essa informação é relevante, pois ratifica que a organização aprendeu e mudou a forma de medir dois indicadores fundamentais para o meio ambiente e para a operação da fábrica, justamente por conta da ISO 14001. Além dessa afirmação, E2 relatou como o SGA foi e está sendo melhorado ao longo do tempo:

Na minha gestão, eu mudei algumas coisas [...] os indicadores de energia elétrica e de água estava ligado ao fator econômico. Então a gente tinha lá, reais por hora entregue, caso a gente tivesse uma boa negociação comercial e abaixasse o preço, aquele indicador cairia, mesmo que o consumo aumentasse. Então, a gente mudou, a gente alterou, se nós pegamos o caso de energia elétrica, o nosso indicador hoje é quilowatts por hora entregue, hora entregue é a hora padrão que a gente entrega de peças por aqui, então a gente focou não no econômico, mas do ponto de vista ambiental, porque é o que interessa pra 14001 (E2).

[...] quando a gente começou com a 14001 e como ele tá hoje, tá bem diferente o sistema. Nós começamos pequenos, de uma forma mais tímida, mas um dos recursos que foram utilizados na implementação foram os kaizens [...] em termos de documentação, a gente, o que tem hoje aqui está aperfeiçoado ao longo do tempo, então a documentação nasceu num eixo bom, mas o que teve que ser aprimorado foram os requisitos legais [...] (E1).

Uma vez que as organizações são coletividades formadas por indivíduos, elas aprendem alguma coisa quando seus membros individuais ou uma parte substancial desses membros aprendem (ARGYRIS; SCHÖN, 1996). A esse respeito, é interessante observar os relatos a seguir: 
A gente começou a fazer uma análise e, do ponto de vista de gestão, eu acho que nós amadurecemos muito [...] os meninos estão na ponta da língua com qualquer coisa em relação à gestão ou atendimento, eles tiraram a coisa do operacional e tão vindo mais [...] eu tô mais como suporte pra prover determinadas coisas pra eles, do que de gestão, eles estão muito bem, muito bom mesmo [...] tão participando de grupo no Sindipeças, tão fazendo coisas com a comunidade que eles não faziam antigamente, ficavam restritos a um ou dois, a gente queria fazer com que eles ampliassem esse leque (E2).

Mas, existe uma parte da aprendizagem que é reforçada, vamos dizer assim, pelas pessoas que têm mais experiência [...] estou falando isso pensando na manutenção. $\mathrm{Na}$ manutenção tinha pessoas experientes lá, e na manutenção tem muita atividade prática, né $[. .].(E 1)$.

No trecho da fala do entrevistado (E2) supracitado, ressalta-se como três funcionários que estão diretamente ligados com a ISO 14001 na organização deixaram de fazer coisas operacionais e aprenderam a pensar de forma mais estratégica e em termos de gestão. Já o outro entrevistado mencionou a importância do aprendizado das pessoas que têm mais vivência dentro da organização. Nos dois relatos, nota-se a clara referência ao aprendizado organizacional como resultado da aprendizagem coletiva de determinada equipe.

O conhecimento organizacional é incorporado nas rotinas e práticas, podendo ser inspecionado e decodificado, mesmo quando os indivíduos que as realizam não são capazes de descrevê-las em palavras (ARGYRIS; SCHÖN, 1996). Um dos entrevistados afirmou que as pessoas mais antigas já sabiam como fazer uma série de atividades relacionadas à ISO $14001 \mathrm{sem}$ pensarem muito naquilo que iriam fazer, deixando claro que esse conhecimento já era inerente a determinados funcionários.

Tem pessoas, principalmente [...] quem ficou trabalhando com assunto mais tempo. Então, por exemplo, se você pega uma pessoa, que nem, por exemplo, o próprio pessoal que trabalha com resíduos aqui. Eles foram orientados, eles foram treinados, retreinados, teve as auditorias, e isso foi reforçando a atividade correta deles [...] (E1).

A aprendizagem organizacional ocorre quando os indivíduos de uma organização experimentam uma situação problemática e, a partir dessa situação, investigam os interesses da organização (ARGYRIS; SCHÖN, 1996). Os entrevistados não relataram que sofreram grandes pressões internas ou externas para implementar a ISO 14001. Contudo, a implementação foi gerada por uma motivação interna, já que a fábrica tinha sido comprada por outra organização que já tinha o sistema, e também por uma motivação externa, pois a os clientes acabavam cobrando a ISO 14001, conforme pode ser observado no relato transcrito a seguir:

A ISO começou a ser implementada aqui em 2001 [...] nós tínhamos implementado a ISO TS na época, e alguns clientes pediam a certificação de ISO 14001 também [...] então eu acho que assim, foi para ter um diferencial no mercado [...] a ISO 14001 estava crescendo no Brasil na época e era meio que novidade, e [...] essa unidade tinha sido incorporada na corporação como um todo, um pouco antes de 2000, e naquela época as outras unidades também já tinham ISO 14001 [...] (E1).

Argyris e Shön (1996) classificam a aprendizagem por meio de ciclos, identificando um ciclo único, um ciclo duplo e um ciclo de deuteroaprendizagem. A aprendizagem de ciclo único está relacionada com a melhor forma de atingir determinado objetivo já existente e de corrigir erros, considerando as normas que já existem nas organizações; a aprendizagem de ciclo duplo compreende a revisão de forma crítica da teoria em uso por meio da indagação dos princípios e das 
regras existentes, que são, então, adequadamente alterados (ARGYRIS; SCHÖN, 1978); e a deuteroaprendizagem é composta de estruturas que canalizam a investigação organizacional e o mundo comportamental da organização, ocorrendo quando a empresa modifica a forma como aprende.

Nas transcrições expostas a seguir, ambas do entrevistado 1 (E1), pode-se analisar à luz do referencial teórico, dois tipos de aprendizagem que a organização obteve por conta da ISO 14001. Trata-se, respectivamente da aprendizagem de ciclo único e da aprendizagem de ciclo duplo:

Então, a gente tem [...] no sistema de gestão da 14001, a gente tem uma matriz que regula todos os principais indicadores, tanto de prevenção, quando de correção e atendimento a legislação.

[...] a gente tem uma análise mensal, a gente pega todos os indicadores, verifica como tá a tendência dos indicadores, se ele tá subindo, se ele tá aumentando, por que está acontecendo.

\section{CONSIDERAÇÕES FINAIS}

Considera-se que o objetivo deste trabalho foi atendido, pois mostra que houve, no processo de implementação e de manutenção da norma ISO 14001, a produção de um produto: a aprendizagem da organização pesquisada. Essa aprendizagem é evidenciada na evolução da tratativa das questões ambientais, que se baseava, antes da implementação da norma, em atender a legislação referente a efluentes e resíduos gerados pela produção. Após a implementação do SGA, houve uma sistematização, uma ampliação e um detalhamento dos itens relacionados ao meio ambiente.

Evidenciou-se, também, que, para manutenção do SGA, é primordial que haja melhoria contínua do sistema. Lacunas vão surgindo e sendo ajustadas ao longo do tempo pelas auditorias subsequentes conforme sugere o ciclo PDCA citado pela ISO 14001. Outro ponto importante refere-se à aprendizagem que ocorreu na organização por meio da melhoria do desempenho de indicadores ambientais, que focalizavam o ponto de vista econômico e passaram a focar o ponto de vista ambiental.

Ao entender a organização como uma coletividade, formadas por indivíduos, constatou-se que houve um progresso substancial no desenvolvimento dos indivíduos que lidam diretamente com as questões ambientais. Estes passaram do nível operacional para o nível da gestão e ampliaram seu campo de atuação, envolvendo-se mais com a comunidade e com os sindicatos.

Conforme o referencial de Argyris e Schön (1996), adotado para identificar a aprendizagem organizacional na empresa pesquisada, ficou evidente o ganho de aprendizado adquirido pela organização ao adotar um SGA baseado na ISO 14001. Apesar disso, uma limitação deste estudo consiste no fato de não terem sido entrevistados outros envolvidos na manutenção do sistema, como funcionários que realizam atividades mais operacionais. A visão apresentada neste estudo é de pessoas que lidam com a gestão do SGA. Nesse sentido, para pesquisas futuras, sugere-se uma amostra maior que envolva tanto a parte de gestão quanto a parte operacional da empresa ou um estudo que envolva empresas de outros setores certificadas pela ISO 14001. 


\section{REFERÊNCIAS}

ABNT. Associação Brasileira de Normas Técnicas. ABNT NBR ISO 14.001:2004, Sistemas da gestão ambiental - Requisitos com orientações para uso. Disponível em: <http:// www.labogef.iesa.ufg.br/labogef/arquivos/ downloads/nbr-iso-14001-2004_70357.pdf> Acesso em: 11 nov. 2014.

ANTAL, A. B.; DIERKES, M.; CHIELD, J.; NONAKA, I. Organizational Learning and Knowledge: reflections on the dynamics of the field and challenges for the future. In: DIERKES, M.; ANTAL, A. B.; CHILD, J; NONAKA, I. (Org.) Handbook of Organizational Learning and Knowledge. Oxford: Oxford University Press, 2001.

ARGYRIS, C.; SCHÖN, D. A. Organizational Learning: a Theory of Action Perspective. Reading/Mass: Addison-Wesley, 1978.

ARGYRIS, C.; SCHÖN, D. A. Organizational learning II: theory, method and practice. New York: Addison-Wesley, 1996.

BARBIERI, J. C. Gestão ambiental empresarial: conceitos, modelos e instrumentos. 3. ed. São Paulo: Saraiva, 2007.

BONTIS, N.; CROSSAN, M.M; HULLAND, J. Managing an organizational learning system by aligning stocks and flows. Journal of Management Studies, v. 39, n. 4, p. 437-469, 2002.

BRASIL. Presidência da República. Lei no 12.305, de 2 de agosto de 2010. Disponível em: http://www.planalto.gov.br/ccivil_03/_ ato2007-2010/2010/lei/l12305.htm. Acesso em: 10 jul. 2015.

CRESWELL, J. W. W. Projeto de pesquisa: métodos qualitativo, quantitativo e misto. 2 . ed. Porto Alegre: Bookman, 2010.

CYERT, R. M.; MARCH, J. G. A Behavorial Theory of the Firm. Englewood Cliffs: Prentice
Hall, 1963.

DIMAGGIO, P. J.; POWELL, W. A gaiola de ferro revisitada: isomorfismo institucional e racionalidade coletiva nos campos organizacionais. Revista de Administração de Empresas, v. 43, n. 2, abr./jun., 2005.

EASTERBY-SMITH, M.; LYLES, M. A. (Ed.). The Blackwell handbook of organizational learning and knowledge management. Oxford: Blackwell Publishing, 2003.

FAUSTINO, F. Brasil atinge a marca de cinco mil certificações em conformidade com a Norma ISO 14001. Revista de Meio Ambiente Industrial, São Paulo, 24 de maio 2011. Disponível em: <http://rmai.com.br/v4/ Read/730/brasil-atinge-a-marca-de-cinco-milcertificacoes-em-conformidade-com-a-normaiso-14001.aspx>. Acesso em: 14 jul. 2015.

GAVRONSKI, I.; PAIVA, E. L.; TEIXEIRA, R.; ANDRADE, M. C. F. ISO 14001 certified plants in Brazil e taxonomy and practices. Journal of Cleaner Production, v. 39, p. 32-41, 2013.

GODOI, C. K.; MATTOS, P. L. C. L. de. Entrevista qualitativa: instrumento de pesquisa e evento dialógico. In: SILVA, A. B. da; GODOI, C. K.; BANDEIRA-DE-MELLO, R. Pesquisa qualitativa em estudos organizacionais: paradigmas, estratégias e métodos. São Paulo: Saraiva, 2006. p. $301-323$

MERRIAM, S. B. Qualitative research in practice. Examples for discussion and analysis. San Francisco: Jossey-Bass, 2002. p. 37-39.

MORGAN, G. Paradigmas, metáforas e resolução de quebra-cabeças na teoria das organizações. Revista de Administração de Empresas, São Paulo, v. 45, n. 1, p. 58-71, 2005.

NONAKA, I. TAKEUCHI, H. Criação de Conhecimento na Empresa. Rio de Janeiro: Ed. Campus, 1995.

PAWLOWSKY, P. The Treatment of Organizational Learning in Management 
Science. In: DIERKES, M.; ANTAL, A. B.; CHILD, $J$; NONAKA, I. Handbook of Organizational Learning and Knowledge. New York: Oxford, 2001.

PEREIRA, S. S.; CURI, R. C. Meio Ambiente, Impacto Ambiental e Desenvolvimento Sustentável: Conceituações Teóricas sobre o Despertar da Consciência Ambiental. Revista de Administração, Ciências Contábeis e Sustentabilidade, v. 2, p. 35-57, 2012.

POMBO, F. R.; MAGRINI, A. Panorama de aplicação da norma ISO 14001 no Brasil. Gestão da Produção São Carlos, v. 15, n. 1, p. 1-10, jan./abr. 2008.

REIS, N. P.; GARCIA, R. L. Sistemas de Gerenciamento dos Resíduos Industriais e Controle Ambiental. In: JARDIM, A; YOSHIDA, C; FILHO, J. V. M. Política Nacional, Gestão e Gerenciamento de Resíduos Sólidos. São Paulo: Manole, 2012.

SINDIPEÇAS. Anuário Desempenho do Setor de Autopeças 2015. Disponível em: http:// www.sindipecas.org.br/noticias/detalhes. php?a=economia\&cod=73\#.ValD-vkYMOU. Acesso em: 17 jul. 2015.

SMITH, P. A. C. The importance of organizational learning for organizational sustainability. The Learning Organization, v. 19 , n. 1, p. 4-10, 2012.

STAKE, R. Case Studies. In: DENZIN, N; LINCOLN, Y. S. Handbook of qualitative research. Thousand Oaks: Sage Publications, 1994. 